\title{
Directive teaching in the community of moral inquiry
}

Philip Cam

\author{
University of New South Wales
}

p.cam@unsw.edu.au

\begin{abstract}
Is there a place for directive teaching when it comes to moral education in the Community of Inquiry? Michael Hand think s that we should make room for it. While some common restrictions on the role of the teacher in the Community of Inquiry and the kinds of questions with which it deals appear to militate against it, he argues that they either have no force or are intellectually or educationally misguided. In evaluating what Hand has to say, I examine the justificatory framework of moral standards within which he sets out his arguments and then look at how those arguments fare in light of that examination.
\end{abstract}

\section{Key words}

community of inquiry, directive teaching, indoctrination, moral education, moral standards, open questions, philosophical attitude

\section{Introduction}

In this issue of the Journal of Philosophy in Schools, Michael Hand argues for an expanded conception of the philosophical classroom Community of Inquiry (CoI) to include what he calls 'directive moral teaching'. By 'directive teaching', he means teaching with 'the aim of persuading pupils that a matter is settled, a claim true or a standard justified' (Hand 2020, p. 14). While this might suggest moral instruction, Hand argues that there are other methods of fulfilling the aim, including procedures that are consistent with the spirit of the CoI, regardless of strictures often placed on it.

Hand responds to three such strictures: avoidance of indoctrination; a focus on open rather than settled questions; and the necessity for teachers to be philosophically self- 
effacing. He needs to do so for obvious reasons. Teaching that aims to have students endorse set moral standards may look like indoctrination. Persuading students that those matters are settled appears to be the direct opposite of opening them up for questioning. Presenting arguments to convince students of pre-established moral conclusions is not philosophically self-effacing.

\section{Justification and moral standards}

Before we consider whether Hand has successfully fended off criticism that may come from these quarters, we need to see how he situates the standards of which he speaks within the moral domain. He spells this out in terms of moral standards being justified, controversial or unjustified. Justified standards are 'those to which there is decisively good reason to subscribe'. Controversial standards are those where 'the arguments for and against subscription are inconclusive'. Unjustified standards are those for which 'there is decisively good reason not to subscribe' (Hand 2020, p. 6).

It is important to note that we are talking about standards in terms of rational justification, without reference to how they are judged on other grounds. A standard may be unjustified in this sense but, say, socially or culturally controversial. Homosexuality, for example, is still not fully accepted in some sectors of Western societies, let alone throughout the rest of the world. That need not prevent moral standards opposing homosexuality from being unjustified in rational terms.

As Hand points out, inquiry into controversial moral standards has a place in everybody's conception of the CoI and there is no question of attempting to persuade students that these matters are settled when they are not. The question is whether directive moral teaching aimed at the other two sets of standards can be successfully incorporated into the CoI.

Clear as this way of setting up the issue appears to be, it runs the danger of treating the moral domain as less philosophically problematic than it is in reality. Hand's justified moral standards are familiar things like 'Do not cheat' and 'Keep your promises' ${ }^{1}$ While these are generally accepted moral standards, they are arguably subject to caveats and qualifications rather than being simple prescriptions. After all, should we always keep our promises? What about when great harm will almost

1 Others he includes are not killing or causing harm, not stealing, extorting or lying, treating others fairly and helping those in need. 
certainly result from doing so, or when it conflicts with other established moral standards, as in having to lie to a third party in order to keep a promise? In other words, there are circumstances in which adherence to them becomes controversial.

Setting this issue aside, it is not obvious that we have the decisive arguments upon which Hand depends. A glance at the history of moral philosophy makes this clear. Think of Kant on the standards just mentioned. Kant is a good example here, as he also has no truck with caveats and qualifications. You should always keep your promises, no matter what! Although Kant takes his arguments to be decisive and generations of Kantians have promulgated them, they are otherwise regarded as controversial, at best. The same is true for all the other arguments with which students of moral philosophy will be familiar, from those associated with Divine Command Theory through to Rule Utilitarianism and beyond. ${ }^{2}$

If the best arguments in philosophy are hardly decisive, commonplace reasons for subscribing to these moral standards are almost certain to fail the test. At their best, they are rudimentary versions of arguments to be found in philosophy. More commonly, however, they tend to be circular or question-begging, as in the following argument: You should not do things of which society disapproves. Society disapproves of cheating and lying. Therefore, you should not cheat or lie. That's a logically valid argument, but it isn't rationally compelling. While the second premise is fact-stating, the first is a moral imperative, so that the argument relies on one moral imperative to derive another.

Hand's examples of unjustified moral standards, such as those proscribing masturbation and homosexual acts, raise a further worry. While injunctions against these things have largely been rejected by Western societies, it is an open question whether the reasons for this are more rationally compelling than arguments to the contrary in other societies. Even if we think they are, it is salutary to remember that arguments against such things were commonly taken to be decisive in our own societies only a generation or two ago. We may have good reasons to disagree with our forebears, as we do with moral standards that pertain in societies quite different from our own, but we should be slow to judge our attempts at justification to be superior to theirs. What we take to be decisive arguments may strike them as

2 In his book A Theory of Moral Education, Hand (2018) presents his own argument to justify accepted moral standards like the ones he mentions here. I have dealt with that argument in my 2019 review for this journal and this is not the place to rehash the matter. Suffice it to say that, while I have sympathy with his argument, I remain to be persuaded that it at last provides the decisive argument for subscription to these standards. 
rationalisations of standards that pertain in our milieu. The proper starting-point, therefore, is to treat these matters as intellectually controversial.

In sum, we should not regard generally accepted moral standards as blanket prescriptions that never occasion controversy. The best arguments for them are inconclusive and themselves subject to controversy. We should also be mindful that reflective people have rationally endorsed standards that we have come to think are unjustified. Rather than taking some standards to be justified and others to be unjustified in that we, unlike others, have the decisive arguments, we should regard them as matters for thoughtful deliberation.

Bearing these things in mind, let's now turn to the issues of indoctrination, open questions and philosophical reticence.

\section{Avoiding indoctrination}

Hand is completely in agreement with the need to avoid indoctrination, but points out that persuading students to endorse or reject a moral standard by presenting decisively good reasons for or against them is not indoctrination. To the extent that we lack such arguments, however, the threat is perfectly real. The teacher who is convinced that these arguments are decisive when they are not faces this danger, especially if the teacher is not schooled in philosophy and the critical examination of arguments.

This does not prohibit the teacher from seeing to it that the students consider what she or he regards as compelling arguments, so long as they are dealt with in the spirit of inquiry. I am in agreement with Hand (2020) when he endorses the benefits of enabling pupils to work out the justification for themselves, through a dialogical process of proposing, testing, critiquing and refining arguments' (p. 12). What worries me is that Hand presents his case in a framework likely to encourage teachers to think that certain arguments are rationally compelling and to explicitly or implicitly present them as such. Many students would be susceptible to this in regarding the teacher as a figure of authority and trust.

We should never forget that indoctrination can take many shades and forms. Such things as brainwashing in cult groups and relentless state propaganda lie at an extreme, but it can take far more subtle and insidious forms, including inadvertent use of a desire to conform and the presumptions of authority in the classroom. 


\section{Open questions}

Hand draws a distinction between a question being open and its being closed but regarded as open in the way that students come to it. Clearly, the knowledge base of the traditional school curriculum relies heavily on the settled findings of inquiries in the disciplines that underpin it, where the related questions are now closed. This does not mean that they can't be opened up again for the purposes of education, providing opportunities for inquiry-based teaching and learning. An elementary finding in physics may be treated as open to question for the sake of a classroom experiment, for example. From this Hand concludes that classroom inquiry need not depend on open questions.

While there's little profit in arguing about nomenclature, a substantive point is at issue here. Properly speaking, a question is only ever open in the sense of being open for some inquirer or inquirers. To say that a question is open in some science, for example, is to say that it is an open question in the relevant scientific community. That might not be so for some other group - say, of religious authorities. For them the question may be closed. Think of the heliocentric theory leading up to Galileo. In that case, those who followed the geocentric conception, insisted on by religious authorities, eventually lost ground to the Copernicans and the matter became closed in the scientific community. As the heliocentric theory became more widely accepted, the question also became closed for the broader community, to the point where we can say that it became regarded as closed without qualification.

The same can be said of so-called common knowledge. Such matters are generally not open to question, but they may be treated that way for educational purposes. The kinds of moral standards that Hand says are justified are much like this. It is a matter of 'common knowledge' that you should not lie or cheat. Still, we might profitably take up the challenge to justify these claims. Following in the tradition of devil's advocate, for instance, we can place those claims in question by arguing against them or demanding their warrant.

This seems to me to be a perfectly acceptable move in moral education, although I am far less sanguine than Hand is about there being anything approaching a proof in these matters. Even so, careful reflection on the best of reasons that may be offered will provide students with a more considered knowledge of the moral terrain and assist them to make better moral judgements. 


\section{Philosophical attitude}

As Hand reminds us, Lipman and Sharp, the original proponents of the CoI, insisted on the teacher modelling the procedures of inquiry rather than providing answers to questions that are under discussion. Does that preclude directive teaching?

While it certainly excludes didactic teaching, Hand points out that directive teaching, unlike didactic teaching, can be inquiry-based. He gives the example of the maths teacher helping students to arrive at an answer to a mathematical problem by guiding them through the operations that lead to it. Nothing in the passages quoted from Sharp and Lipman preclude the teacher from doing the same by guiding students through a sound argument to whatever conclusion it implies. Far from it. As with the teacher guiding students through mathematical deduction, teaching students to work through arguments while paying careful attention to soundness and validity is partand-parcel of modelling the procedures of philosophical inquiry.

The problem lies not in helping to guide students through an argument to its conclusion, but in the presumption on the part of Hand's teacher that he or she is in possession of a non-question-begging argument from true and uncontroversial premises to a statement of some moral standard as conclusion. So far as I can see, that is almost certain not to be the case. If I am right, then the teacher clearly faces the danger of being substantively committed when they shouldn't be and of drifting into indoctrination.

Even if the teacher may not be in possession of logically decisive arguments, Hand is right to resist the idea of epistemic equality in the CoI. Teachers should know their way around their subject matter better than their pupils. Classroom inquiry is different in this respect from academic discussion among equals. This requires teachers to be directive in all kinds of ways, including the selection of subject matter, planning the way that it will be dealt with, and being responsible for its delivery. When we get down to detail, not the least of those responsibilities is seeing to it that, as occasion demands, the strongest arguments are discussed.

This does not preclude epistemic modesty and open-mindedness on the part of the teacher where the subject matter requires it. Nowhere is this more pertinent than when it comes to arguments in the field of ethics. It would have been helpful if Hand had exhibited some of the supposedly decisive arguments upon which his case depends, as no rational defence of our common ethical standards that I know of has proved to be decisive. This is not to deny that philosophers have presented arguments that some 
have found persuasive, but only to point out that the best of them remain controversial. The appropriate response to this, it seems to me, is to approach those arguments in an open-minded way and to treat claims to indisputable knowledge with caution.

None of this is to deny that we have reason to adopt certain moral standards and reject others. We may even allow that those reasons are good enough for practical purposes. After all, we need to get on with our lives and the best that we have got will have to do. To talk about decisively good reasons in philosophy, however, is to appeal to a higher standard. While professional standards of argumentation obviously do not apply to the school classroom, there is no case for presenting arguments as logically conclusive when they are not.

Things like epistemic modesty and open-mindedness also speak to what we may call a philosophical attitude. It can make us hesitate to lay claim to knowledge where others do not fear to tread. There is good reason for this. As Plato's Socrates shows over and again, to realise that you don't really know something on the basis of decisive good reason is often the beginning of wisdom in regard to the matter and the startingpoint for educating yourself about it.

\section{Conclusion}

The examination of moral standards is a proper part of moral education and that includes inquiring into their justification. The classroom philosophical CoI clearly provides a venue for this. In addition to controversial cases and moral dilemmas, it affords the opportunity to examine the rational foundations of existing moral standards and those to which our society no longer subscribes.

To explore the strengths and weaknesses of various lines of argument in the spirit of inquiry does not preclude the teacher from directing students' attention to particular arguments and helping them to examine them. It is important for students to be able to see why an argument fails, remains inconclusive, or is decisive. At the same time, the teacher should be careful not to overestimate the strength of an argument because it leads to a socially approved or rejected conclusion. That is both a logical error and a step down the slippery slope of indoctrination.

It can be challenging to question existing moral standards, but it is a very good way of beginning to see what is to be said for them. Likewise, entertaining standards that 
have been rejected can help us to appreciate what is to be said against them. Such critical scrutiny is certainly of educational value and may lead students to endorse or reject a standard by appeal to reason rather than simply because of the social pressure to conform. The danger of it lies not in turning students into moral sceptics, but of teachers unwittingly leading them to overestimate the strength of an argument which, as novices, they may all too easily do. That risk is all the greater if the teachers do likewise. If anything, an argument of which you are convinced calls for even greater scrutiny and a preparedness to find error.

There can be a case for feigning ignorance, as in Socratic irony, but teachers must actually know their way around their subject matter far better than their pupils if they are to instruct them in it. Even so, they still need to exercise epistemic humility and open-mindedness and not to pretend to knowledge that they do not possess. Philosophers have spent centuries inconclusively debating the relevant arguments in ethics and so teachers should proceed with caution.

\section{References}

Cam, P (2019) Review of 'A theory of moral education'. Journal of Philosophy in Schools, 6(1), pp. 116-120.

Hand, M (2018) A theory of moral education. Routledge, London.

Hand, M (2020) Moral education in the community of inquiry. Journal of Philosophy in Schools, (7)2, pp. 4-20. 